\title{
Farelo de mesocarpo de babaçu (Orbygnia sp.) na terminação de bovinos: composição física da carcaça e qualidade da carne
}

\author{
Babassu mesocarp bran for finishing cattle: carcass physical composition and meat quality
}

\author{
Fabrícia Rocha Chaves Miotto ${ }^{\mathrm{I}^{*}}$ João Restle ${ }^{\mathrm{II}}$ José Neuman Miranda Neiva $^{\text {III }}$ \\ Pedro Leonardo de Paula Resende ${ }^{\mathrm{I}}$ Moacir Evandro Lage ${ }^{\mathrm{IV}}$ Cristiano Sales Prado $^{\mathrm{IV}}$ \\ João Teodoro PaduaII Vera Lúcia de Araújo ${ }^{I I I}$
}

RESUMO

Foram avaliadas a composição tecidual da carcaça e as características qualitativas da carne de 30 tourinhos mestiços (18,9 meses e 346,8kg iniciais) alimentados com dietas formuladas com diferentes proporções de farelo de mesocarpo de babaçu (Orbygnia sp.) em substituição ao milho: 0 ; 25; 50; 75 e 100\% de substituição. Os animais foram abatidos com peso médio de $476,7 \mathrm{~kg}$. A porcentagem de músculo na carcaça aumentou de forma linear: 0,022\% para cada ponto percentual de inclusão de farelo de mesocarpo de babaçu (FMB). Por sua vez, os percentuais de gordura e osso da carcaça variaram de forma quadrática, sendo a maior proporção de gordura observada quando a substituição de milho por FMB na dieta foi de $25 \%$ e a menor proporção de osso obtida com $50 \%$ de substituição. A relação porção comestível:osso foi maior com $42,5 \%$ de substituição do milho por FMB. À medida que se elevou a proporção de FMB nas dietas, houve decréscimo na espessura do coxão, escore muscular e compacidade da carcaça. A força de cisalhamento da carne teve acréscimos de $44 \mathrm{kgf}$ para cada ponto percentual de substituição do milho por FMB. Quanto à composição química da carne, verificou-se aumento no teor de matéria mineral. $O$ uso de FMB em dietas de terminação de bovinos reduziu a maciez da carne, não alterando as demais características qualitativas.

Palavras-chave: confinamento, maciez, musculosidade, porção comestível, subprodutos.

\section{ABSTRACT}

We evaluated the carcass composition and meat qualitative characteristics, of 30 young crossbred bulls (18.9 months and $346.8 \mathrm{~kg}$ ) fed with diets with different proportion of babassu mesocarp bran (BMB) (Orbygnia sp.); replacing corn: 0, 25, 50, 70 and 100\% substitution. The percentage of muscle in the carcass increased linearly, $0.022 \%$ for each percentage point of including $B M B$ and the percentages of fat and bone had a quadratic response in which adipose tissue has increased until the replacement of $25 \%$ and bone tissue decreased to $50 \%$ substitution. The ratio of edible portion: bone increased up to $42.5 \%$. As the levels of BMB increased, a decrease in cushion thickness, muscle score and carcass compactness occurred. The shear force of meat was increased by $44 \mathrm{kgf}$ for each percentage point of corn replacement. For the physical-chemical composition we observed an increase in the meat mineral matter. The use of BMB in finishing diets for beef cattle reduced the tenderness of the meat, not altering the other qualitative characteristics.

Key words: byproducts, edible portion, feedlot, meat tenderness, muscularity.

\section{INTRODUÇÃO}

O farelo de mesocarpo de babaçu (FMB) (Orbygnia sp.) é um produto residual da industrialização do babaçu para produção de biodisel, sendo utilizado como substituto do milho em dietas de bovinos na Região Norte do Brasil, por apresentar, em certos períodos do ano, preços 65\% menores do que os praticados para aquele produto, reduzindo o custo das dietas. Embora a utilização de alimentos possa

'Programa de Pós-graduação em Ciência Animal (PPGCA), Universidade Federal de Goiás (UFG), 77804-970, Goiânia, GO, Brasil. E-mail: fabriciarchaves@hotmail.com. *Autor para correspondência.

IIDepartamento de Produção Animal, PPGCA, UFG, Goiânia, GO, Brasil.

IIIEscola de Medicina Veterinária e Zootecnia (EMVZ), Universidade Federal do Tocantins (UFT), Araguaína, TO, Brasil.

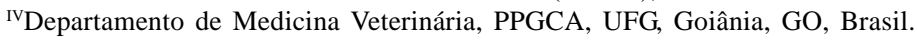


refletir em melhoria na viabilidade econômica dos sistemas de produção, mudanças nos ingredientes de dietas de terminação podem promover modificações na composição física da carcaça e em importantes atributos qualitativos da carne, de importância relevante tanto para os consumidores como para a indústria frigorífica (ROEBER et al., 2005; BRONDANI et al., 2006).

Segundo FELÍCIO (1997), a carne vermelha pode ser classificada quanto aos seguintes atributos de qualidade: nutricionais, visuais, gustativos e de segurança. Os atributos nutricionais são determinantes do desejo do consumidor, pois criam imagem favorável ou desfavorável do produto. Já os atributos visuais, como a cor, e os gustativos, como a maciez e a suculência, são aspectos que atraem ou repelem o consumidor, fazendo com que volte ou não a adquirir o produto. Nesse sentido, a literatura atual não contempla estudos sobre os efeitos do FMB na composição tecidual da carcaça e características qualitativas da carne, informações importantes como suporte para avaliação da real viabilidade de uso deste subproduto. Objetivou-se com este trabalho avaliar o efeito do uso do farelo de mesocarpo de babaçu em substituição ao milho em dietas de confinamento, sobre a composição física da carcaça e características qualitativas da carne de bovinos.

\section{MATERIAL E MÉTODOS}

O trabalho foi realizado no município de Araguaína, localizada na região Norte do Tocantins, 07¹1'28”' de Latitude Sul, e 4812'26”' de Longitude Oeste. Trinta tourinhos $1 / 2$ Pardo Suíço $\times 1 \frac{1}{2}$ Nelore $(18,9$ meses de idade inicial) foram terminados em confinamento durante 105 dias, alimentados individualmente com dietas contendo cinco proporções de FMB em substituição ao milho: 0; 25; 50; 75 e 100\%. As dietas foram compostas por $80 \%$ de concentrado e $20 \%$ de volumoso, formuladas com o auxílio do programa RLM 3.1 ${ }^{\circledR}$ (Tabela 1). O FMB possuía 86,3\% de matéria seca (MS); 3,1\% de proteína bruta (PB); $45,0 \%$ de fibra em detergente neutro (FDN); 32,0\% de FDA; $0,64 \%$ de extrato etéreo (EE); 4,6\% de matéria mineral e $61,1 \%$ de desaparecimento in situ da MS (incubação ruminal por 240 horas). A composição

Tabela 1 - Proporção de ingredientes e composição bromatológica de dietas, para terminação de tourinhos, contendo farelo de mesocarpo de babaçu em substituição ao milho.

\begin{tabular}{|c|c|c|c|c|c|}
\hline \multirow{2}{*}{ Ingredientes (\% matéria seca) } & \multicolumn{5}{|c|}{-Níveis de substituição, \%- } \\
\hline & 0 & 25 & 50 & 75 & 100 \\
\hline Silagem de Mombaça & 20,00 & 20,00 & 20,00 & 20,00 & 20,00 \\
\hline FMB & 0,00 & 16,25 & 32,50 & 48,75 & 65,00 \\
\hline Milho & 65,00 & 48,75 & 32,50 & 16,25 & 0,00 \\
\hline Farelo de soja & 10,93 & 10,90 & 10,90 & 10,90 & 10,88 \\
\hline Ureia & 0,00 & 0,36 & 0,71 & 1,06 & 1,42 \\
\hline Calcário & 1,57 & 1,24 & 0,89 & 0,54 & 0,20 \\
\hline Núcleo mineral $^{1}$ & 2,50 & 2,50 & 2,50 & 2,50 & 2,50 \\
\hline Matéria seca (\% matéria mineral) & 73,97 & 73,17 & 73,20 & 72,69 & 72,48 \\
\hline Proteína bruta ${ }^{2}$ & 11,10 & 11,35 & 11,66 & 12,22 & 12,73 \\
\hline Fibra em detergente neutro $^{2}$ & 30,72 & 32,15 & 36,79 & 41,67 & 45,73 \\
\hline Fibra em detergente ácido² & 14,70 & 18,20 & 21,48 & 27,58 & 30,28 \\
\hline Hemicelulose $^{2}$ & 16,01 & 14,13 & 15,31 & 14,08 & 15,47 \\
\hline Carboidratos totais $^{2}$ & 78,56 & 79,20 & 78,73 & 77,77 & 76,14 \\
\hline Carboidratos não estruturais ${ }^{2}$ & 47,84 & 47,06 & 41,94 & 36,10 & 30,41 \\
\hline Extrato etéreo ${ }^{2}$ & 2,92 & 2,34 & 2,08 & 1,91 & 1,55 \\
\hline Matéria mineral $^{2}$ & 7,42 & 7,11 & 7,53 & 8,10 & 9,59 \\
\hline Nutrientes digestíveis totais, $\%^{2}$ & 74,43 & 65,45 & 56,82 & 49,87 & 52,75 \\
\hline ELm, Mcal dia ${ }^{-1}$ & 7,00 & 7,11 & 7,11 & 7,02 & 6,94 \\
\hline ELg, Mcal dia ${ }^{-1}$ & 6,40 & 6,69 & 7,41 & 6,40 & 5,53 \\
\hline
\end{tabular}

${ }^{1}$ Vantage Núcleo Peso (Agroquima Produtos Agropecuários LTDA) - Ca - 143g; P - 40g; S - 35g; Na - 90g; Mg - 15g; Zn - 1.500mg; MM - 35mg; Cu - 500mg; Co - 50mg; I - 50mg; Se - 6mg; Vitamina A -100.000U.I; Vitamina E - 150U.I; Monensina sódica - 1.400mg; Bicarbonato de sódio - 200g; ${ }^{2} \%$ da matéria seca. ELm - energia líquida de mantença; ELg - energia líquida de ganho.

Ciência Rural, v.42, n.7, jul, 2012. 
bromatológica da silagem de mombaça, utilizada como fração volumosa da dieta, citada na mesma ordem, foi 25,1; 5,6; 81,7; 55,2; 3,0; 11,22 e 59,6\%.

O escore muscular (FORNI et al., 2007) foi avaliado antes do abate, observando-se a cobertura muscular do corpo do animal com ênfase no traseiro; classificou-se de 1 a 5 em pontuação contínua, em que 1 foi dado a animais muito deficientes em massa muscular; 2 para os deficientes; 3 para os de massa regular; 4 para boa e 5 para os de excelente massa muscular. Os animais foram abatidos em frigorífico comercial, seguindo-se a rotina de abate da indústria e normas do Serviço de Inspeção Federal. Após 24 horas de resfriamento $\left(0\right.$ a $\left.2^{\circ} \mathrm{C}\right)$, as carcaças foram avaliadas para conformação e maturidade fisiológica (MÜLLER, 1987) e, nas meias carcaças direitas, realizaram-se as mensurações do perímetro do braço e espessura do coxão. Na altura da $12^{\mathrm{a}}$ costela foi desenhada em papel vegetal a área exposta do músculo Longissimus dorsi (LD), a qual foi mensurada utilizando-se o programa AutoCad $^{\circledR}$, expressa em $\mathrm{cm}^{2}$ e corrigida para $100 \mathrm{~kg}$ de carcaça fria. A compacidade da carcaça foi calculada pela relação entre o peso da carcaça fria $(\mathrm{kg})$ e comprimento da carcaça $(\mathrm{cm})$.

A avaliação das características subjetivas da carne como cor, marmoreio e textura, foi realizada na face exposta do músculo LD, correspondente a $12^{a}$ costela, após 30 minutos de exposição ao ar (MÜLLER, 1987). A composição física da carcaça foi estimada segundo HANKINS \& HOWE (1946). Após separação física, o músculo LD foi identificado, embalado e imediatamente congelado. Posteriormente, foram retirados, de cada porção do músculo, dois bifes com espessura de $2,5 \mathrm{~cm}$ cada, pesados, identificados, colocados em bandejas de alumínio e levados para descongelamento em refrigerador, a $4^{\circ} \mathrm{C}$. Depois de descongelados, foram novamente pesados para obtenção da perda de peso na forma de líquidos durante o descongelamento. Após esse processo, os bifes foram colocados em bandejas individuais previamente pesadas e assados em forno elétrico até atingir $70^{\circ} \mathrm{C}$ de temperatura interna, monitorada com auxílio de termômetro. Posteriormente, foram novamente pesados, com e sem bandeja, para obtenção da perda de líquidos durante o processo de cozimento. Foram extraídos oito feixes circulares com $1,0 \mathrm{~cm}^{2}$ de área por bife, os quais foram cortados perpendicularmente à fibra e submetidos à leitura da força necessária para o cisalhamento das fibras musculares no aparelho texturômetro com lâmina Warner-Bratzler. Foram desprezados o valor máximo e o mínimo para efeito de análise. O segundo bife foi utilizado para realização de análises químicas da carne, sendo determinados a umidade e os teores de proteína, EE e minerais (SILVA \& QUEIROZ, 2002).

Os animais foram distribuídos em delineamento inteiramente casualizado, com cinco tratamentos e seis repetições. O modelo estatístico geral para análise de variância foi: $\gamma_{\mathrm{ij}}=\mu+\tau_{\mathrm{i}}+\varepsilon_{\mathrm{ij}}$ em que: $\gamma_{\mathrm{ij}}$ $=$ variável dependente; $\mu=$ média geral; $\tau_{\mathrm{i}}=$ efeito do tratamento $\mathrm{i}$; e $\varepsilon_{\mathrm{ij}}=$ erro experimental residual. Foi adotada probabilidade de 0,05 para o teste F. As variâncias foram testadas quanto à normalidade e à homocedasticidade. No estudo de regressão, o modelo foi: $\gamma_{i j}=\beta_{0}+\beta_{1} X_{i}+\beta_{2} X_{i}^{2}+\beta_{3} X_{i}^{3}+\alpha_{j_{+}} \varepsilon_{i j}$, em que: $\gamma_{i j}=$ variáveis dependentes; $\beta$ 's = coeficientes de regressão; $\mathrm{X}_{\mathrm{i}}=$ proporções de substituição do milho por FMB; $\alpha_{j}=$ desvios da regressão; e $\varepsilon_{\mathrm{ij}}=$ erro aleatório residual. As variáveis dependentes também foram avaliadas quanto à correlação de Pearson.

\section{RESULTADOS E DISCUSSÃO}

O uso do FMB em substituição ao milho proporcionou aumento linear na porcentagem de músculo na carcaça; $0,022 \%$ para cada $1 \%$ de substituição do milho pelo FMB (Tabela 2). A porcentagem de gordura apresentou ligeira elevação até o nível de $25 \%$ de substituição do milho por FMB, em que o tecido adiposo atinge 20,11\% da carcaça, declinando para 15,61\% com 100\% de substituição do milho pelo FMB, conforme a equação de regressão. Destaca-se, entretanto, que a elevação obtida no presente estudo é de pouca importância, considerando que a dieta sem FMB proporcionou 19,61\% de tecido adiposo na carcaça. Porém, a partir de 50\% de substituição do milho pelo FMB, observou-se decréscimo acentuado deste tecido, em que a carcaça dos animais alimentados com a dieta com $100 \%$ de substituição apresentou teor de gordura 20,39\% menor que a daqueles alimentados com dietas contendo apenas milho como fonte de energia.

A produção absoluta de músculo é o produto do PCF e da proporção deste na carcaça. Embora a porcentagem de músculo tenha aumentado linearmente frente aos níveis de FMB, a quantidade de músculo em valor absoluto não foi alterada (Tabela 2), o que é explicado pela queda no peso da carcaça, que reduziu linearmente com o aumento da proporção do FMB nas dietas. O valor absoluto do tecido ósseo não foi alterado pelos tratamentos, no entanto, a quantidade de gordura teve comportamento quadrático com ponto de máxima em 26,7\% de substituição, proporcionando quantidade máxima estimada de gordura de 50,92kg na carcaça.

Dessa forma, pode-se inferir que a variação na quantidade absoluta de gordura na carcaça foi 
Tabela 2 - Composição física da carcaça e características que expressam a musculosidade da carcaça de tourinhos terminados com dietas contendo farelo de mesocarpo de babaçu.

\begin{tabular}{|c|c|c|c|c|c|c|c|c|c|}
\hline \multirow{2}{*}{ Variáveis } & \multicolumn{5}{|c|}{------------Níveis de substituição, \%------------ } & \multirow{2}{*}{ Valor $\mathrm{P}^{1}$} & \multirow{2}{*}{ Equação } & \multirow{2}{*}{ Erro padrão } & \multirow{2}{*}{$r^{2}$} \\
\hline & 0 & 25 & 50 & 75 & 100 & & & & \\
\hline Peso inicial, kg & 344,2 & 352,0 & 345,0 & 346,0 & 346,8 & 0,98 & $Y=346,8$ & 5,60 & - \\
\hline Peso final, kg & 474,7 & 483,8 & 489,0 & 474,6 & 461,2 & 0,49 & $\mathrm{Y}=476,7$ & 7,05 & - \\
\hline Rendimento de carcaça, \% & 53,3 & 53,4 & 52,6 & 50,9 & 50,5 & $<0,001$ & $Y=53,74-0,032 x$ & 0,34 & 43,0 \\
\hline PCF, kg & 247,0 & 252,4 & 253,4 & 236,6 & 228,4 & 0,02 & $Y=254,88-0,25 x$ & 3,72 & 18,24 \\
\hline Músculo, \% & 65,4 & 65,9 & 66,5 & 66,8 & 67,8 & 0,02 & $Y=65,32+0,022 x$ & 0,36 & 17,1 \\
\hline Gordura, \% & 19,7 & 20,1 & 19,8 & 18,9 & 16,2 & 0,03 & $Y=19,61+0,04 x-0,0008 x^{2}$ & 0,45 & 35,4 \\
\hline Osso, \% & 15,4 & 14,8 & 14,6 & 15,0 & 16,2 & 0,001 & $Y=15,44-0,04 x+0,0004 x^{2}$ & 0,16 & 38,1 \\
\hline Músculo, kg & 161,4 & 166,0 & 168,1 & 158,0 & 154,9 & 0,18 & $\mathrm{Y}=161,68$ & 2,24 & - \\
\hline Gordura, kg & 48,8 & 51,0 & 50,3 & 44,6 & 37,0 & 0,02 & $Y=48,79+0,16 x-0,003 x^{2}$ & 1,54 & 38,4 \\
\hline Osso, kg & 38,1 & 37,4 & 37,1 & 35,5 & 36,9 & 0,30 & $\mathrm{Y}=37,01$ & 0,58 & - \\
\hline PC:O & 5,6 & 5,8 & 5,9 & 5,7 & 5,2 & 0,001 & $Y=5,53+0,017 x-0,0002 x^{2}$ & 0,07 & 36,7 \\
\hline $\mathrm{M}: \mathrm{O}$ & 4,3 & 4,4 & 4,5 & 4,5 & 4,2 & 0,01 & $Y=4,24+0,012 x-0,0001 x^{2}$ & 0,05 & 21,9 \\
\hline M:G & 3,4 & 3,3 & 3,4 & 3,6 & 4,2 & 0,03 & $Y=3,40-0,01 x+0,0002 x^{2}$ & 0,10 & 34,0 \\
\hline CC, pontos ${ }^{2}$ & 11,2 & 11,5 & 10,8 & 10,7 & 10,7 & 0,06 & $Y=10,96$ & 0,14 & - \\
\hline $\mathrm{ALD}, \mathrm{cm}$ & 67,6 & 66,7 & 67,6 & 66,2 & 63,3 & 0,25 & $Y=66,24$ & 1,11 & - \\
\hline $\mathrm{ALD} / 100$ & 27,5 & 26,5 & 26,7 & 28,0 & 27,7 & 0,50 & $Y=27,26$ & 0,40 & - \\
\hline $\mathrm{EC}, \mathrm{cm}$ & 25,8 & 25,1 & 25,3 & 23,9 & 23,3 & $<0,001$ & $Y=25,9-0,022 x$ & 0,25 & 41,74 \\
\hline PBR, cm & 36,7 & 37,0 & 37,1 & 36,3 & 36,4 & 0,50 & $\mathrm{Y}=36,70$ & 0,24 & - \\
\hline EM, pontos ${ }^{3}$ & 3,4 & 3,2 & 3,1 & 2,9 & 2,8 & $<0,001$ & $Y=3,34-0,005 x$ & 0,06 & 35,66 \\
\hline Compacidade, kg/cm & 1,8 & 1,8 & 1,8 & 1,7 & 1,7 & 0,002 & $Y=1,86-0,002 x$ & 0,02 & 27,82 \\
\hline
\end{tabular}

${ }^{1}$ Valor P - probabilidade; ${ }^{2}$ Boa menos- 10 pontos; Boa típica - 11 pontos; Boa mais - 12 pontos; ${ }^{3}$ Massa muscular: $1=$ muito deficiente; 2=deficiente; 3=regular; 4=boa; 5=excelente; ; PCQ - Peso da carcaça quente; PCF - Peso da carcaça fria; PC:O - Porção comestível:osso; M:O - músculo:osso; M:G - músculo:gordura, CC- conformação; ALD - área do músculo Longissimus dorsi; ALD/100 - área do músculo Longissimus dorsi corrigido para 100kg de carcaça fria; EC - espessura do coxão; PBR - perímetro do braço; EM - escore muscular.

responsável pelas variações das proporções dos demais tecidos. Foi observada correlação negativa entre as proporções de músculo e gordura $(\mathrm{r}=-0,85$; $\mathrm{P}<0,001)$ e de gordura e osso da carcaça $(\mathrm{r}=-0,56$; $\mathrm{P}=0,001)$. Enquanto a variação percentual entre o maior e o menor valor da participação de tecido adiposo na carcaça foi de $19,4 \%$, esta foi de apenas 3,7\% para a participação de tecido muscular. A quantidade de gordura depositada é determinada por diversos fatores, entre eles a densidade energética da dieta. BRONDANI et al. (2006) verificaram que o incremento de energia na dieta promoveu aumento da porcentagem de músculo na carcaça, contudo sem haver variação na porcentagem de gordura. Com a melhoria do teor energético da dieta, maior desenvolvimento muscular é esperado, porém a melhor forma de expressar este fato é a deposição de gordura (BERG \& BUTTERFIELD, 1976; BRONDANI et al., 2006). Provavelmente, neste trabalho, a variação na composição adiposa das carcaças ocorreu em função da variação nos teores de energia líquida de ganho (ELg). Na tabela 1 pode-se observar que houve aumento na ELg para as dietas com 25 e $50 \%$ de substituição do milho, com posterior redução da ELg nas dietas com 75 e 100\% de substituição. Esta variação na partição de energia pode ter comprometido a deposição de tecido adiposo para animais alimentados com elevadas proporções de FMB.

A porcentagem de osso teve comportamento quadrático decrescendo até $50 \%$ de substituição, sendo elevada a partir deste ponto. A não alteração da quantidade absoluta de músculos na carcaça demonstrou que a substituição do milho por FMB foi capaz de manter o ganho desse tecido pelos animais, contudo, substituições acima de $25 \%$ podem prejudicar a deposição de gordura, importante na proteção dos músculos da carcaça durante o resfriamento e na apresentação dos cortes cárneos. Com as variações nos tecidos, verificaram-se também modificações em suas relações, todas apresentando comportamento quadrático (Tabela 2). A relação porção comestível:osso (PC:O) aumentou até 42,5\% de substituição do milho por FMB, resultado obtido basicamente em função do comportamento da quantidade de gordura da carcaça. A relação músculo:osso (M:O) teve ponto de máxima em 
60\% de FMB em substituição ao milho e a relação músculo:gordura (M:G) teve ponto mínimo em $25 \%$ de substituição. PACHECO et al. (2005) consideraram fundamental estudar a relação entre músculo e gordura na carcaça, mediante à preocupação com a ingestão de gordura e seus efeitos sobre a saúde (triglicerídeos). Para a indústria frigorífica e mercado varejista, é importante buscar melhores relações $\mathrm{M}: \mathrm{O}$ e músculo + gordura (PC):osso, já que estes tecidos compreendem a porção de tecido comercializável da carcaça, determinando melhores rendimentos da desossa. Porém, o peso da carcaça também é importante para frigoríficos e varejistas, por determinar o tamanho dos cortes e quantidade comercializável, assim como também é importante para o produtor que recebe pelo peso da carcaça vendida ao frigorífico. Dessa forma, embora o uso de FMB em substituição ao milho tenha proporcionado relações favoráveis de tecidos na carcaça, a redução de peso desta é um ponto negativo da substituição e deve ser prevista quando da formulação das dietas e do planejamento do tempo de terminação.

A conformação das carcaças (CC) não foi influenciada pelas dietas, recebendo classificação boa menos (Tabela 2). Carcaças com melhor CC são preferidas por apresentarem músculos com melhor aparência, menor proporção de osso e maior porção comestível (MÜLLER, 1987). Essas afirmações são confirmadas pelas correlações observadas nesse trabalho, em que a CC foi correlacionada negativamente com a porcentagem de osso $(\mathrm{r}=-, 48 ; \mathrm{P}=0,006)$ e positivamente com as relações $\mathrm{PC}: \mathrm{O}(\mathrm{r}=0,48 ; \mathrm{P}=0,006)$ e $\mathrm{M}: \mathrm{O}(\mathrm{r}=0,44 ; \mathrm{P}=0,014)$.

A inclusão de FMB não influenciou a área do Longissimus dorsi (ALD) tanto em $\mathrm{cm}^{2}$, quanto em $\mathrm{cm}^{2} 100 \mathrm{~kg}^{-1}$ de carcaça. Verificou-se correlação mediana entre esta característica e a quantidade de músculo da carcaça, $\mathrm{r}=0,63(\mathrm{P}<0,001)$. Assim, a não variação do valor da ALD nos diferentes tratamentos é explicada pela semelhança entre as quantidades absolutas de tecido muscular na carcaça. O PCF e o peso de abate também foram correlacionados positivamente com a ALD, $\mathrm{r}=0,55$ $(\mathrm{P}=0,001)$ e $\mathrm{r}=0,46(\mathrm{P}=0,01)$, respectivamente. A espessura do coxão (EC), outra característica associada à musculosidade da carcaça, decresceu com o aumentou da inclusão de FMB na dieta, provavelmente devido à queda no PCF, com correlação entre estas variáveis de $0,55(\mathrm{P}=0,001)$. O escore muscular (EM) dos animais diminuiu com a substituição do milho pelo FMB, em que as dietas com 75 e 100\% de FMB apresentaram escores inferiores a 3,0 (musculatura regular a deficiente), porém sem haver modificação da quantidade de tecido muscular depositado na carcaça. O EM correlacionou-se positivamente com as quantidades absolutas de músculo e gordura e $\mathrm{PC}: \mathrm{O}$ ( $\mathrm{r}=0,44$ e $\mathrm{P}=0,014 ; \mathrm{r}=0,41$ e $\mathrm{P}=0,024 ; \mathrm{r}=0,40$ e $\mathrm{P}=0,024$, respectivamente), e correlação negativa com o percentual de osso da carcaça $(r=-0,40 ; \mathrm{P}=0,025)$. Também foi correlacionado positivamente com formas importantes de avaliação da musculosidade da carcaça, correlacionando-se com a CC ( $\mathrm{r}=0,63 ; \mathrm{P}=0,0002)$, a ALD $(\mathrm{r}=0,39 ; \mathrm{P}=0,032)$, a $\mathrm{EC}(\mathrm{r}=0,77 ; \mathrm{P}<0,0001)$, demonstrando ser um método relevante para avaliação do animal vivo.

A compacidade da carcaça foi reduzida com aumento da inclusão de FMB na dieta, diminuindo a quantidade de quilos por centímetro de comprimento de carcaça, na dimensão de 2 gramas para cada ponto percentual. A compacidade correlacionou-se positivamente com o $\mathrm{PCF}(\mathrm{r}=0,94 ; \mathrm{P}<0,0001)$, além da EGS e PC:O ( $\mathrm{r}=0,55$ e $\mathrm{P}=0,001 ; \mathrm{r}=0,40$ e $\mathrm{P}=0,026$; respectivamente), também sendo correlacionada com a CC ( $r=0,41$ e $\mathrm{P}=0,023)$, ALD ( $\mathrm{r}=0,63$ e $\mathrm{P}<0,001)$, EC $(\mathrm{r}=0,69$ e $\mathrm{P}<0,001)$ e $\mathrm{PBR}(\mathrm{r}=0,53$; $\mathrm{P}<0,001)$.

As características que avaliam a qualidade da carne, marmoreio em pontos e corrigido para $100 \mathrm{~kg}$ de carcaça fria, textura e cor, não foram influenciadas pela substituição do milho pelo FMB (Tabela 3). A carne apresentou cor vermelha, sendo o marmoreio classificado como traços e a textura foi de grosseira a muito grosseira. A substituição do milho por FMB também não modificou as perdas por descongelamento, cozimento e perdas totais da carne.

Houve aumento na força de cisalhamento (FC) da carne à medida que aumentaram as proporções de FMB (Tabela 3). Para cisalhar a carne nos tratamentos contendo 25; 50; 75 e 100\% de substituição foi necessário empregar força 36,4; 65,5; 96,4 e 90,1\% maior do que aquela utilizada para a carne dos animais alimentados com a dieta exclusivamente com milho como fonte de energia. A força de cisalhamento da carne e a maciez subjetiva da carne (escala descrita por MÜLLER, 1987; 1 = carne extremamente dura e 9 = carne extremamente macia) apresentam correlações negativas que variam de médias a altas ( $\mathrm{r}=-0,47$, VAZ \& RESTLE, 2002, e r=-0,87, VAZ et al., 2007). SHACKELFORD et al. (1991) propuseram que valores de cisalhamento acima de 9,0kgf caracterizam “carnes duras”, abaixo de 6,0kgf “carnes macias" e entre 6,0 e 9,0kgf estariam carnes com "maciez intermediária”. Mais recentemente, SHACKELFORD et al. (1999) determinaram valor de cisalhamento de 5,0kgf como limiar da maciez. VAZ et al. (2007) observaram que 9,23kgf foi considerado pelo painel sensorial como carne de maciez levemente acima da média, e VAZ et al. (2002) verificaram que o emprego da força de cisalhamento de 5,5 a 6,1kgf proporcionou carne considerada macia. Dessa forma, verifica-se que 
Tabela 3 - Características qualitativas da carcaça e da carne de tourinhos terminados em confinamento com dietas contendo farelo de mesocarpo de babaçu.

\begin{tabular}{|c|c|c|c|c|c|c|c|c|c|}
\hline \multirow{2}{*}{ Variáveis } & \multicolumn{5}{|c|}{------------Níveis de substituição, \%------------ } & \multirow{2}{*}{ Valor P. ${ }^{1}$} & \multirow{2}{*}{ Equação } & \multirow{2}{*}{ Erro padrão } & \multirow{2}{*}{$r^{2}$} \\
\hline & 0 & 25 & 50 & 75 & 100 & & & & \\
\hline MM, pontos ${ }^{2}$ & 2,7 & 2,9 & 2,5 & 3,2 & 2,5 & 0,661 & $\mathrm{Y}=2,91$ & 0,16 & - \\
\hline $\mathrm{MM} / 100$ & 1,1 & 1,3 & 1,1 & 1,3 & 1,1 & 0,960 & $\mathrm{Y}=1,19$ & 0,06 & - \\
\hline TEX, pontos ${ }^{3}$ & 2,5 & 2,7 & 2,9 & 2,9 & 2,3 & 0,486 & $\mathrm{Y}=2,69$ & 0,14 & - \\
\hline Cor, pontos ${ }^{4}$ & 2,5 & 3,0 & 3,2 & 3,2 & 3,1 & 0,213 & $\mathrm{Y}=3,00$ & 0,11 & - \\
\hline $\mathrm{PD}, \%$ & 11,5 & 12,3 & 13,2 & 16,2 & 15,9 & 0,961 & $Y=13,81$ & 1,19 & - \\
\hline PC, \% & 22,3 & 20,0 & 24,8 & 23,0 & 24,2 & 0,229 & $\mathrm{Y}=22,84$ & 1,09 & - \\
\hline PT, \% & 31,1 & 29,6 & 34,7 & 36,4 & 36,2 & 0,432 & $\mathrm{Y}=33,60$ & 1,17 & - \\
\hline EGS, mm & 3,4 & 3,2 & 3,7 & 2,8 & 1,9 & 0,02 & $\mathrm{Y}=3,29+0,02 \mathrm{x}-0,0003 \mathrm{x}^{2}$ & 0,17 & 39,23 \\
\hline FC, kgf & 5,5 & 7,5 & 9,1 & 10,8 & 10,5 & 0,009 & $Y=6,6+0,044 x$ & 0,63 & 21,7 \\
\hline MF, pontos & 13,0 & 13,2 & 12,8 & 12,8 & 13,0 & 0,857 & $\mathrm{Y}=12,93$ & 0,13 & - \\
\hline Umidade, \% & 74,9 & 74,8 & 74,9 & 75,0 & 75,5 & 0,227 & $Y=75,01$ & 0,15 & - \\
\hline Proteína, \% & 22,5 & 23,4 & 22,6 & 23,0 & 23,0 & 0,621 & $\mathrm{Y}=22,92$ & 0,21 & - \\
\hline $\mathrm{EE}, \%$ & 2,4 & 2,2 & 2,3 & 2,0 & 1,9 & 0,131 & $\mathrm{Y}=2,16$ & 0,12 & - \\
\hline Minerais, \% & 3,6 & 3,8 & 3,7 & 3,9 & 4,0 & 0,003 & $Y=3,6+0,003 x$ & 0,04 & 27,0 \\
\hline
\end{tabular}

${ }^{1}$ Valor P - probabilidade ; ${ }^{2} 1=$ traços menos, $2=$ traços típico, $3=$ traços mais ; ${ }^{3} 1=$ muito grosseira; $2=$ grosseira, $3=$ levemente grosseira, 4 = fina; ${ }^{4} 1$ = escura; 2 = vermelho escura, 3 = vermelho levemente escura, 4 = vermelho; MM - marmoreio; MM/100 marmoreio corrigido para 100kg de carcaça fria; TEX- textura; PD - perdas no descongelamento; PC - perdas no cozimento; PT - perdas totais; EGS - espessura de gordura subcutânea - FC - força de cisalhamento, MF - maturidade fisiológica; EE - extrato etéreo.

a carne avaliada neste trabalho pode ser classificada com maciez acima da média, no entanto, a literatura demonstra respostas variadas na relação entre a maciez subjetiva e a força de cizalhamento, em que vários fatores são determinantes desta, em especial o limiar de aceitação do consumidor.

Um dos fatores que influencia negativamente a maciez da carne é o encurtamento pelo frio. Segundo FELÍCIO (1997), a redução rápida da temperatura dos músculos, que geralmente ocorre quando estes são expostos a temperaturas menores que $10^{\circ} \mathrm{C}$ no início do desenvolvimento do rigor mortis, pode provocar o endurecimento da carne, sendo mais frequente em carcaças relativamente leves e magras. A redução da musculosidade das carcaças com o aumento de FMB ficou evidenciada neste trabalho pelas características de EM, EC e compacidade da carcaça (Tabela 2). Contudo, observou-se correlação significativa da FC apenas com a EC ( $\mathrm{r}=-0,35 ; \mathrm{P}=0,05)$. Em seu estudo, HEINEMANN et al. (2003) demonstraram que animais abatidos com pesos mais elevados apresentaram queda mais lenta da temperatura interna do LD, fato atribuído à maior musculosidade das carcaças, verificaram ainda a ocorrência de maiores EGS e correlação negativa entre a FC e a EGS $(-0,43)$ e a ALD (-0,49). A cobertura de gordura subcutânea é importante na prevenção do encurtamento pelo frio. Neste trabalho, a EGS teve comportamento quadrático com máxima EGS com 33,3\% de substituição, reduzindo a partir de então. Dessa forma, espera-se que esta tenha contribuído parcialmente para o aumento da resistência da carne ao cisalhamento.

Os teores de umidade, proteína e EE no músculo LD não apresentaram diferença (Tabela 3). Já o teor de minerais teve acréscimo com a substituição de milho por FMB. O milho utilizado neste trabalho apresentou 1,6\% de minerais, 2,6 vezes menos do que o verificado para o FMB. Na formulação das dietas, buscou-se suprir as necessidades diárias dos macronutrientes Ca e P com a adição de calcário, porém foi verificado que, à medida que o FMB foi aumentando nas dietas, houve elevação dos teores de minerais (Tabela 1), refletindo na maior deposição destes na carne. KAZAMA et al. (2008), avaliando subprodutos, não verificaram modificações na composição nutritiva do músculo LD, com valores médios de 73,36; 22,98; 
2,6; $1,04 \%$ para umidade, proteína, gordura e minerais, respectivamente.

\section{CONCLUSÃO}

O uso do farelo de mesocarpo de babaçu em substituição ao milho em dietas de confinamento para bovinos não altera as características qualitativas da carne como cor e marmoreio, porém, por promover redução acentuada na maciez, o uso do farelo de mesocarpo não é recomendado em mercados que valorizam e remuneram esta característica. Além disso, apesar da substituição do milho por farelo de mesocarpo proporcionar melhoria da relação porção comestível:osso, até a substituição de 42,5\%, e músculo:osso, até $60 \%$, por diminuir o peso da carcaça, o seu uso deve ser feito após cuidadosa análise da relação custo/benefício.

\section{AGRADECIMENTOS}

Os autores agradecem à TOBASA Bioindustrial de Babaçu, à Fazenda Barra Bonita, à Agroquima Produtos Agropecuários e ao Frigorífico Boi forte, pela parceria. Os autores F.C.M. Miotto e P.L.P. Resende eram bolsistas de doutorado do Conselho Nacional de Desenvolvimento Científico e Tecnológico (CNPq). Os autores J. Restle e J.N.M. Neiva são bolsistas de Produtividade em Pesquisa do CNPq. A pesquisa foi parcialmente financiada pelo CNPq.

\section{COMITÊ DE ÉTICA E BIOSSEGURANÇA}

Protocolo no 289/2010.

\section{REFERÊNCIAS}

BERG, R.T.; BUTTERFIELD, R.M. New concepts of cattle growth. Sydney: Sydney University, 1976. 240p.

BRODANI, I.V. et al. Composição física da carcaça e aspectos qualitativos da carne de bovinos de diferentes raças alimentados com diferentes níveis de energia. Revista Brasileira de Zootecnia, v.35, n.5, p.2034-2042, 2006. Disponível em: <http:/ /www.scielo.br/scielo.php?script=sci_arttext\&pid=S1516$35982006000700022 \& \operatorname{lng}=e n \& n r m=i s o \& t \operatorname{lng}=p t>$. Acesso em: 04 fev. 2011. doi: 10.1590/S1516-35982006000700022.

FELICIO, P.E. de. Fatores que influenciam na qualidade da carne bovina. In: PEIXOTO, A.M. et al. (Org.). Produção de novilho de corte. Piracicaba: FEALQ, 1997. p.79-97.

FORNI, S. et al. Tendências genéticas para escores visuais de conformação, precocidade e musculatura à desmama de bovinos Nelore. Revista Brasileira de Zootecnia, v.36, n.3, p.572577, 2007. Disponível em: <http://www.scielo.br/pdf/rbz/v36n3/ a08v36n3.pdf $>$. Acesso em: 17 jun. 2011.

HANKINS, O.G.; HOWE, P.E. Estimation of composition of beef carcasses and cuts. Washington, D.C.: USDA, 1946. 20p. (Tecnical Bulletin USDA, 926).
HEINEMANN, R.J.B. et al. Fatores que influenciam a textura da carne de novilhos Nelore e cruzados Limousin-Nelore. Pesquisa Agropecuária Brasileira, v.38, n.8, p.963-971, 2003. Disponível em: <http://www.scielo.br/scielo.php?script= sci_arttext\&pid=S0100204X2003000800009\&lng=en\&nrm=isso $>$. Acesso em: 02 fev. 2011. doi: 10.1590/S0100204X2003000800009.

KAZAMA, R. et al. Características quantitativas e qualitativas da carcaça de novilhas alimentadas com diferentes fontes energéticas em dietas à base de cascas de algodão e de soja. Revista Brasileira de Zootecnia, v.37, n.2, p.350-357, 2008. Disponível em: <http://www.revistasbz.org.br/scripts/revista/ sbz1/Artigos/6423.PDF>. Acesso em: 03 fev. 2011. doi: 10.1590/S1516-35982008000200023.

MÜLLER, L. Normas para avaliação de carcaças e concurso de carcaças de novilhos. 2.ed. Santa Maria: Universidade Federal de Santa Maria, 1987. 31p.

PACHECO, P.S. et al. Composição física da carcaça e qualidade da carne de novilhos jovens e superjovens de diferentes grupos genéticos. Revista Brasileira de Zootecnia, v.34, n.5, p.16911703, 2005. Disponível em: <http://www.revistasbz.org.br/ scripts/revista/sbz1/Artigos/4433.PDF>. Acesso em: $03 \mathrm{fev}$. 2011. doi: 10.1590/S1516-35982005000500031.

ROEBER, D.L. et al. Meat quality responses to feeding distiller's grains to finishing Holstein steers. Journal Animal Science, v.83, p.2455-2460, 2005. Disponível em: <http://jas.fass.org/ cgi/reprint/83/10/2455>. Acesso em: 04 fev. 2011.

SHACKELFORD, S.D. et al. Identification of threshold levels for warner-bratzler shear force in beef top loin steaks. Journal of Muscle Foods, v.2, p.289-296, 1991.

SHAKELFORD, S.D. et al. Tenderness classification of beef: II. Design and analysis of a system to measure beef Longissimus shear force under commercial processing conditions. Journal of Animal Science, v.77, p.1474-1481, 1999. Disponível em: <http://jas.fass.org/content/77/6/1474.full.pdf+html>. Acesso em: 10 out. 2011.

SILVA, D.J.; QUEIROZ, A.C. Análise de alimentos: métodos químicos e biológicos. 3.ed. Viçosa, MG: UFV, 2002. 235p.

VAZ, F.N.; RESTLE, J. Aspectos qualitativos da carcaça e da carne de machos Braford superprecoces, desmamados aos 72 ou 210 dias de idade. Revista Brasileira de Zootecnia, v.31, n.5, p.2078-2087, 2002. Disponível em: <http://www.scielo.br/ pdf/rbz/v31n5/a23v31n5.pdf>. Acesso em: 05 out. 2011.

VAZ, F.N. et al. Características de carcaça e da carne de novilhos superprecoces de três grupos genéticos, gerados por fêmeas de dois anos. Revista Brasileira de Zootecnia, v.31, n.5, p.19731982, 2002. Disponível em: <http://dx.doi.org/10.1590/ S151635982002000800013>. Acesso em: 05 out. 2011.

VAZ, F.N. et al. Qualidade da carcaça e da carne de novilhos abatidos com pesos similares, terminados em diferentes sistemas de alimentação. Ciência Animal Brasileira, v.8, n.1, p.3140, 2007. Disponível em: <http://www.revistas.ufg.br/index. php/vet/article/view/1156/1246>. Acesso em: 05 out. 2011. 